\title{
Aminododecyldiphosphonic Acid for Solvent Extraction of Bismuth Ions
}

\author{
Baghdad Medjahed ${ }^{1}$, M'Hamed Kaid ${ }^{1}$, Mohamed Amine Didi ${ }^{1 *}$, Didier Villemin ${ }^{2}$ \\ ${ }^{1}$ Laboratory of Separation and Purification Technology, Department of Chemistry, \\ Faculty of Sciences, Tlemcen University, Tlemcen, Algeria \\ ${ }^{2}$ Laboratoire de Chimie Moléculaire et Thioorganique, UMR CNRS 6507, \\ INC3M, FR 3038, Labex EMC3, ENSICAEN, Caen, France \\ Email: *madidi13@yahoo.fr
}

Received July 29, 2012; revised September 8, 2012; accepted September 20, 2012

\begin{abstract}
The extraction of Bi(III) in nitrate media has been investigated using aminododecyldimethylenediphosphonic acid, ADDMDPA, which was previously synthesized and characterized. The extraction of the cation was carried out in different media with the addition of $\mathrm{CH}_{3} \mathrm{COONa}, \mathrm{KNO}_{3}$ and $\mathrm{HNO}_{3}$. The maximum extraction yield for Bismuth is $70 \%$ after addition of $0.01 \mathrm{M}$ of potassium nitrate at $\mathrm{pHi}=2.9$, in one step.
\end{abstract}

Keywords: Bismuth(III); Aminododecyldimethylenediphosphonic Acid; Solvent Extraction

\section{Introduction}

Bismuth is used in the cosmetics industry for the preparation of creams and hair dyes, while some of its colloidal salts (subcitrate and subgallate), due to their antiseptic, astringent and diuretic properties, have important applications in pharmaceutical preparations and are employed as anti-ulcer, antibacterial, anti-HIV and radiotherapeutic agents [1].

World reserves of bismuth are usually obtained as a sub-product in lead, copper, tin and gold ores [2-4]. During the industrial metallurgical process of these ores, leaching stages with $\mathrm{H}_{2} \mathrm{SO}_{4}, \mathrm{HCl}$ and $\mathrm{HNO}_{3}$ are involved, and highly acidic solutions with base metals and bismuth are obtained $[5,6]$.

Bismuth is a curious metal and could be toxic in an unsuitable form $[2,7]$. Its metal extraction is a major challenge in the metal addressing the environmental pollution, its mode of physiopathological action was little studied and it is not yet understood [6,7].

The synthesis of new organophosphorus extractants which form stable complexes with metallic species is of great importance for improving existing hydrometallurgycal processes for their recovery $[8,9]$.

In fact, we have synthesized aminododecyldimethylenediphosphonic acid for such a purpose. The characterization of this product was achieved using various spectroscopic methods including $\left({ }^{1} \mathrm{H}\right.$ NMR, ${ }^{31} \mathrm{P}$ NMR, ${ }^{13} \mathrm{C}$ NMR, FTIR and the like).

"Corresponding author.
We have studied this acid in the recovery of metal species $\mathrm{Bi}^{+3}$ under the optimal conditions in different media, in one step.

\section{Experimental}

\subsection{Reagents and Solutions}

The reagents used in this work were dodecan, phosphorus acid (35\%) from (Aldrich). HCHO and Bismuth nitrate was purchased from Merck. The aqueous solutions concentrations of $\mathrm{Bi}(\mathrm{III})$ in nitrate medium taken as $0.5 \mathrm{mmol} \cdot \mathrm{L}^{-1}$ and the organic (ADDMDPA) solution concentration was taken from 0.5 to $10 \mathrm{mmol} \cdot \mathrm{L}^{-1}$.

\subsection{Instrumentation}

${ }^{13} \mathrm{C}\left\{-{ }^{1} \mathrm{H}\right\},{ }^{31} \mathrm{P}\left\{-{ }^{1} \mathrm{H}\right\}$ and ${ }^{1} \mathrm{H}$ NMR spectra were measured on a Bruker $\mathrm{AC} 250$ working at $250 \mathrm{MHz}$ in a $\mathrm{CDCl}_{3}$ solution. Infrared spectra were measured on a Perkin Elmer 16 PC-FTIR equipped with a thermostat to maintain the temperature of the sample at $25.0^{\circ} \mathrm{C} \pm 0.1^{\circ} \mathrm{C}$. A Phywe WTM 320 with combined glass electrode was used to measure the $\mathrm{pH}$ of the aqueous solution before and after extraction. In a water-acetone mixture (15:5), a known mass of the ADDMDPA was titrated with a solution of $\mathrm{NaOH}\left(5 \mathrm{mmol} \cdot \mathrm{L}^{-1}\right)$. Metal ions were determined using the electrothermal atomic absorption GFAAS, system GBC 932, and system 3000 automated graphite furnace (GBC Scientific Equipment, Dandenong, Australia). Background correction was made with a deuterium lamp 
and pyrolytic graphite tubes were used. Settings such as lamp current, wavelength, temperature programs, and slit width were those recommended in the operating manual.

\subsubsection{Synthesis of the Extractant and Characterization}

ADDMDPA was synthesized following a method first described by Largman et al. [6] with an original modification developed in our laboratory [7]. The product presented the following properties, and its formula is shown in Figure 1. Formula: $\mathrm{CH}_{3}-\left(\mathrm{CH}_{2}\right)_{11} \mathrm{~N}\left(\mathrm{CH}_{2} \mathrm{P}(\mathrm{O})(\mathrm{OH})_{2}\right)_{2}$ IR U ( $\left.\mathrm{cm}^{-1}\right)$ : 2750(vas PO), 1120 (vs PO), 1015 (vas P-OH), 966 s P-OH); 1H NMR $\left(\mathrm{D}_{2} \mathrm{O}, \mathrm{Na}_{2} \mathrm{CO}_{3}\right) \delta / \mathrm{TMS}$ (ppm): 1.35 (s, 4H, $\mathrm{CH}_{2}$ ), $1.75\left(\mathrm{~m}, 12 \mathrm{H}, \mathrm{CH}_{2}\right), 3.125$ (d, $\left.{ }^{2} \mathrm{~J}_{\mathrm{HP}}=8.92 \mathrm{NCH}_{2}-\mathrm{P}\right), 3.35\left(\mathrm{~m}, 2 \mathrm{H}, \mathrm{N}-\mathrm{CH}_{2}\right) ;{ }^{31} \mathrm{P} \mathrm{NM}-$ $\mathrm{R}\left(\mathrm{D}_{2} \mathrm{O}, \mathrm{Na}_{2} \mathrm{CO}_{3}\right): \delta / \mathrm{H}_{3} \mathrm{PO}_{4}(\mathrm{ppm}) 8.78 ;{ }^{13} \mathrm{C} \mathrm{NMR}\left(\mathrm{D}_{2} \mathrm{O}\right.$, $\mathrm{Na}_{2} \mathrm{CO}_{3}$ ) (ppm):13.5 (s, C $\left.\mathrm{C}_{1}\right), 17.14\left(\mathrm{~s}, \mathrm{C}_{2}\right), 30\left(\mathrm{~s}, \mathrm{C}_{3}\right), 50$ $\left(\mathrm{d},{ }^{2} \mathrm{~J}_{\mathrm{CP}}=138.7, \mathrm{NCH}_{2}-\mathrm{P}\right)$.

The obtained pKai: $3.25,8.4$ and 9.3 indicated that in water-acetone medium, the fourth acidity is not attained corresponding to very weak acidity.

The presence of $\mathrm{P}=\mathrm{O}$ wide band indicates hydrogen intermolecular bonds $\mathrm{P}=\mathrm{O} \cdot \mathrm{H}-\mathrm{OP}$ and $\mathrm{N} \mid \cdot>\mathrm{H}-\mathrm{O}-\mathrm{P}$.

The ADDMDPA is soluble in most organic solvents, and shows intermolecular hydrogen bonding, forming polymers depending on the solvent polarity [10].

Thus, in chloroform that we used in our study, the ADDMDPA is generally present in a dimeric form, as shown in Figure 1 [11,12].

\subsubsection{Extraction Experiments}

The extraction experiments were carried out with ADDMDPA dissolved in chloroform. After various preliminary tests with different solvents, chloroform has been chosen since it dissolves the extractant without trouble or emulsion.

The appropriate volume of the aqueous solution (10 $\mathrm{mL}$ ) containing the metal ion and the ADDMDPA (aqueous/organic volume ratio of $1: 1$ ) were mixed in glass flasks.

The mixtures were shaken in a moderate way, for at least 6 min for $\mathrm{Bi}(\mathrm{III})$. All the experiments were carried out at $20^{\circ} \mathrm{C}$.

\section{Results and Discussion}

The results of the extraction experiments will be dis-

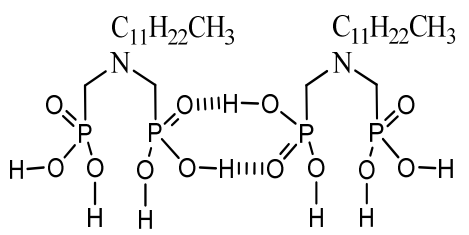

Figure 1. Dimeric form of ADDMDPA. cussed in terms of the distribution coefficient, D, and the extraction yield, Y [13].

$$
\begin{aligned}
& \mathrm{D}=\left(\frac{\mathrm{m}_{\mathrm{i}}-\mathrm{m}_{\mathrm{f}}}{\mathrm{m}_{\mathrm{f}}}\right) \times \frac{\mathrm{V}_{\mathrm{aq}}}{\mathrm{V}_{\mathrm{org}}} \\
& \mathrm{Y}(\%)=\frac{\mathrm{m}_{\mathrm{i}}-\mathrm{m}_{\mathrm{f}}}{\mathrm{m}_{\mathrm{i}}} \times 100
\end{aligned}
$$

with the variables being as follows: $\mathrm{m}_{\mathrm{i}}$ : initial mass of metal ion in the aqueous phase; $\mathrm{m}_{\mathrm{f}}$ : mass of metal ion in the aqueous phase after extraction; $\mathrm{V}_{\text {org }}$ : volume of the organic phase; $\mathrm{V}_{\mathrm{aq}}$ : volume of the aqueous phase.

The molar ratio $\mathrm{Q}$ is defined as the ratio of the number of moles of the ligand in the organic phase versus the number of moles of metal in the aqueous phase before extraction.

$$
\mathrm{Q}=\frac{\mathrm{n}_{\text {extractant }}}{\mathrm{n}_{\text {metal }}}
$$

\subsection{Extraction Kinetics}

The equilibrium times were $6 \mathrm{~min}$ for $\mathrm{Bi}(\mathrm{III})$. The results are shown in Figure 2.

Figure 2 shows that the maximum extraction yield was obtained after 6 min of moderate shaking

\subsection{Effect of the Molar Ratio}

Figure 3 shows that the optimal extractant concentration that gives the maximum yield (52\%) was 2 that correspond to extactant concentration equal to $1 \mathrm{mmol}$.

The stoichiometric coefficients obtained from the plots $\ln \mathrm{D}$ vs $\ln$ [AADDMDP] and $\ln \mathrm{D}$ vs pHeq, shown in Figures 4 and 5 respectively, may suggest the reaction mechanism in neutral media. This result led us to propose the following extraction equilibrium.

$$
\overline{2 \mathrm{Bi}^{3+}+6 \mathrm{NO}_{3}+\overline{3\left(\mathrm{AH}_{4}\right)_{2}}} \overline{\left(\mathrm{AH}_{3} \mathrm{AH}_{4}\right) \mathrm{Bi}_{2}\left(\mathrm{AH}_{4} \mathrm{AH}_{4}\right)_{2}}, 5\left(\mathrm{NO}_{3}\right)^{-}+\mathrm{H}^{+}, \mathrm{NO}_{3}^{-}
$$

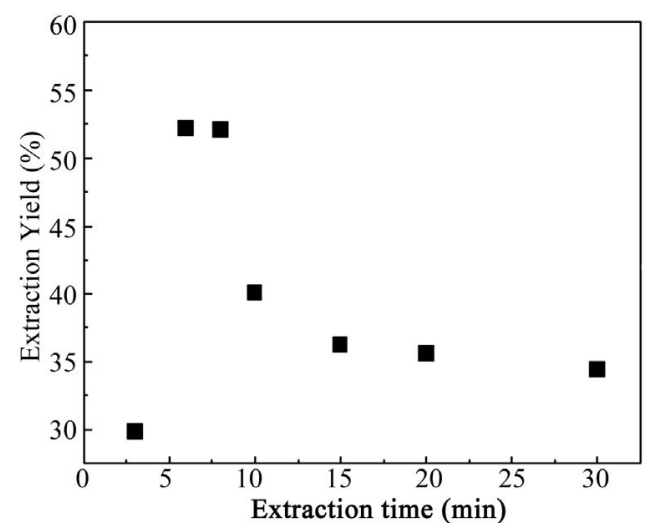

Figure 2. Extraction kinetics of $\mathrm{Bi}(\mathrm{III}) ;\left[\mathrm{Bi}^{+3}\right]_{0}=5 \times 10^{-4} \mathrm{M}$, $[\text { ADDMDPA }]_{0}=10^{-3} \mathrm{M}, \mathrm{Vaq} / \mathrm{Vorg}=1, \mathrm{~T}=20^{\circ} \mathrm{C}, \mathrm{pHi}=2.9$. 


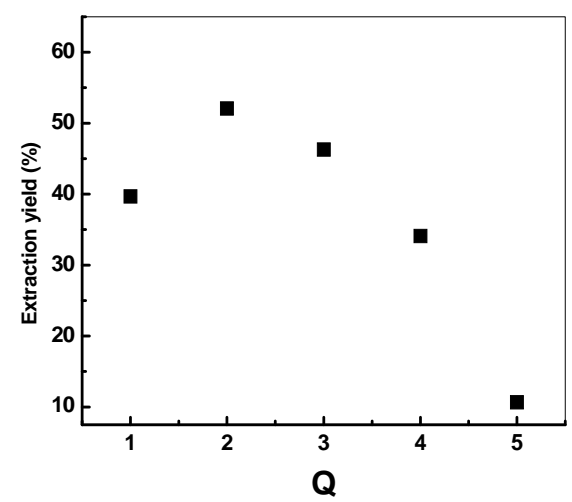

Figure 3. Effect of the molar ratio on the extraction yield of $\mathrm{Bi}$ (III) in nitrate medium; $\left[\mathrm{Bi}^{3+}\right]_{0}=5 \times 10^{-4} \mathrm{M}, \mathrm{Vaq} /$ Vorg $=$ $1, t=6 \min , T=20^{\circ} \mathrm{C}$.

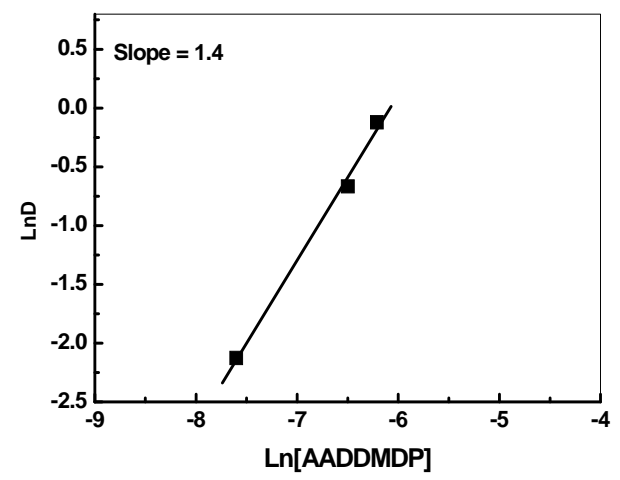

Figure 4. Effect of extractant concentration on the distribution ratio of $\mathrm{Bi}(\mathrm{III}) . \mathrm{T}=20^{\circ} \mathrm{C}, \mathrm{Vaq} /$ Vorg $=1$.

The AADDMDP extracts in cationic exchange mode with substantial yields because the extractions are done to only one cycle.

\subsection{Influence of the Ionic Strength on the Extraction of $\mathbf{B i}^{3+}$}

The influence of the ionic strength on the extraction yields of Bi(III) with AADDMDP diluted in chloroform, was studied by adding potassium nitrate and sodium acetate to the aqueous phase at the same concentration $0.01 \mathrm{M}$.

The yield of extraction of $\mathrm{Bi}(\mathrm{III})$ decreases with the increase of concentration of the sodium acetate in aqueous phase.

According to these results, it is noticed that the addition of $\mathrm{CH}_{3} \mathrm{COONa}$ decreases the extraction yield, on the other hand the addition of $\mathrm{KNO}_{3}$ increased it to $70 \%$. This is due probably to the basic medium imposed by the sodium acetate; consequently we were interested to the study of the evolution of the yield according to the variation of the concentration of $\mathrm{KNO}_{3}$ in the aqueous phase.

\subsection{Effect of the Addition of $\mathrm{KNO}_{3}$}

In order to study the influence of the ionic force on the

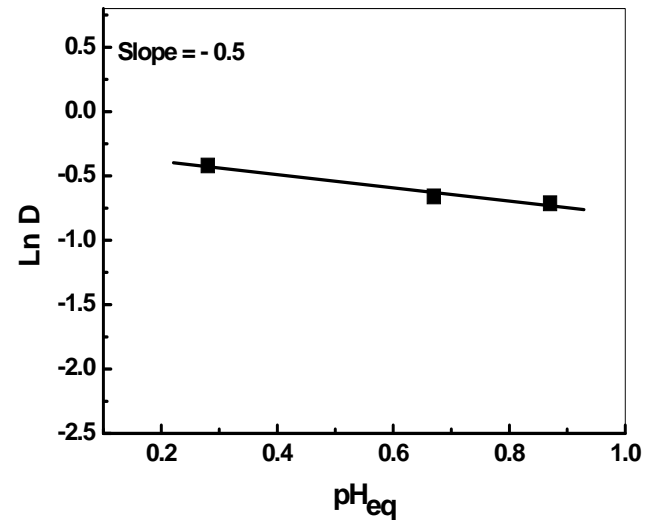

Figure 5. Effect of equilibrium $\mathrm{pH}$ on the distribution ratio of Bi(III).

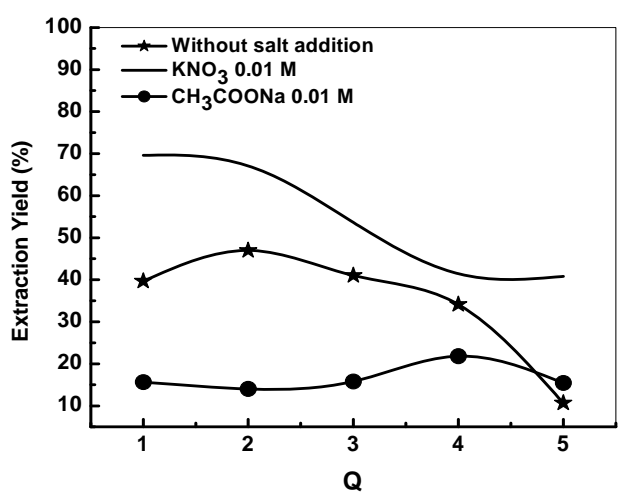

Figure 6. Effects of molar ratio on the extraction yield, with and without salt addition.

extraction of $\mathrm{Bi}^{3+}$, three quantities of $\mathrm{KNO}_{3}$ were added to the aqueous phase before extraction.

According to these results, after the addition of $\mathrm{KNO}_{3}$ $0.01 \mathrm{M}$, the yield is $70 \%$ with $\mathrm{Q}=1$. In the interval of $0.1-1 \mathrm{M}$, the increase of the concentration of $\mathrm{KNO}_{3}$ will have a negative effect on the extraction yield, because of the competition between the two cations $\left(\mathrm{K}^{+}, \mathrm{Bi}^{3+}\right)$.

The stoichiometric coefficients obtained from the plots Log E vs. Log [AADDMDP] and Log E vs. pHeq, shown in Figures 8 and 9 respectively may suggest the reaction mechanism of bismuth extraction.

The slopes are respectively equal to $(0.75)$ near to 1 for extractant and 1 for the $\mathrm{pH}$.

The equilibrium equation is written as follows:

$$
\begin{aligned}
& \mathrm{Bi}^{3+}+3 \mathrm{NO}_{3}^{-}+\overline{\left(\mathrm{AH}_{4}\right)_{2}} \rightleftharpoons \\
& \overline{\mathrm{Bi}\left(\mathrm{AH}_{3} \mathrm{AH}_{4}\right) 2\left(\mathrm{NO}_{3}^{-}\right)}+\mathrm{H}^{+}, \mathrm{NO}_{3}^{-}
\end{aligned}
$$

\subsection{Effect of Nitric Acid on the Extraction of Bi (III)}

We note that in acidic media, the extraction yield decreases drastically reaching a minimum of $5 \%$. 


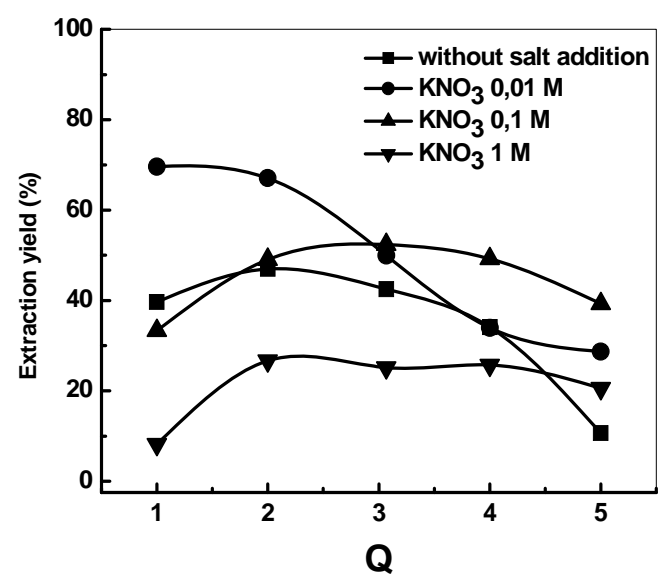

Figure 7. Effects of molar ratio on the extraction yield after the addition of potassium nitrate $\left[\mathrm{Bi}^{3+}\right]=5 \times 10^{-4} \mathrm{M}, \mathrm{Vaq} /$ Vorg $=1, t=6 \mathrm{~min}, \mathrm{~T}=20^{\circ} \mathrm{C}$.

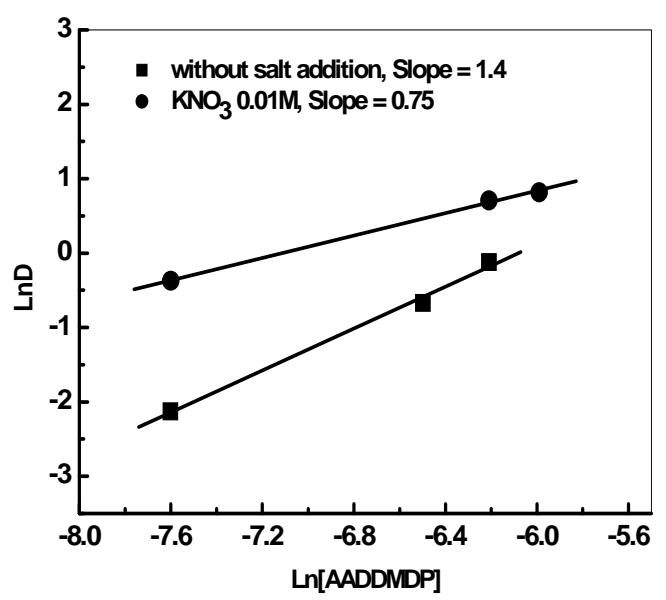

Figure 8. Effect of extractant concentration on the distribution ratio of $\mathrm{Bi}(\mathrm{III})$ before and after addition of potassium nitrate. $\left[\mathrm{Bi}^{3+}\right]=5.10^{-4} \mathrm{M}, \mathrm{Vaq} /$ Vorg $=1, \mathrm{t}=6 \mathrm{~min}, \mathrm{~T}=20^{\circ} \mathrm{C}$.

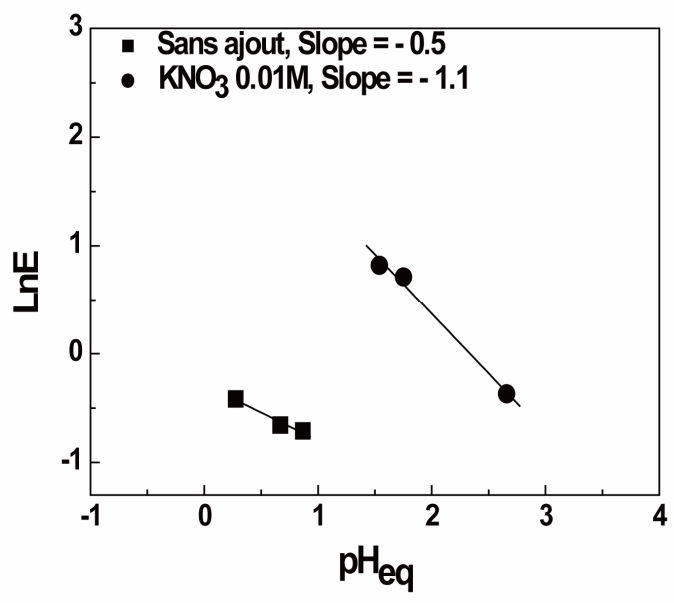

Figure 9. Effect of equilibrium pH on the distribution ratio of $\mathrm{Bi}$ (III) before and after addition of potassium nitrate. $\left[\mathrm{Bi}^{3+}\right]_{0}=5 \times 10^{-4} \mathrm{M}, \operatorname{Vaq} / \operatorname{Vorg}=1, \mathrm{t}=6 \mathrm{~min}, \mathrm{~T}=20^{\circ} \mathrm{C}$.

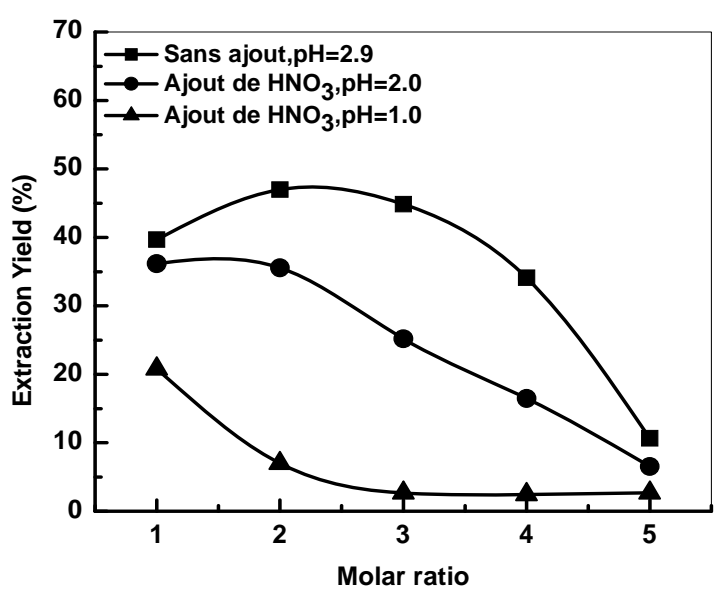

Figure 10. Effect of $\mathrm{pH}$ on the extraction yield $\left[\mathrm{Bi}^{3+}\right]=5 \times$ $10^{-4} \mathrm{M}$, Vaq $/$ Vorg $=1, \mathrm{t}=6 \mathrm{~min}, \mathrm{~T}=25^{\circ} \mathrm{C}$.

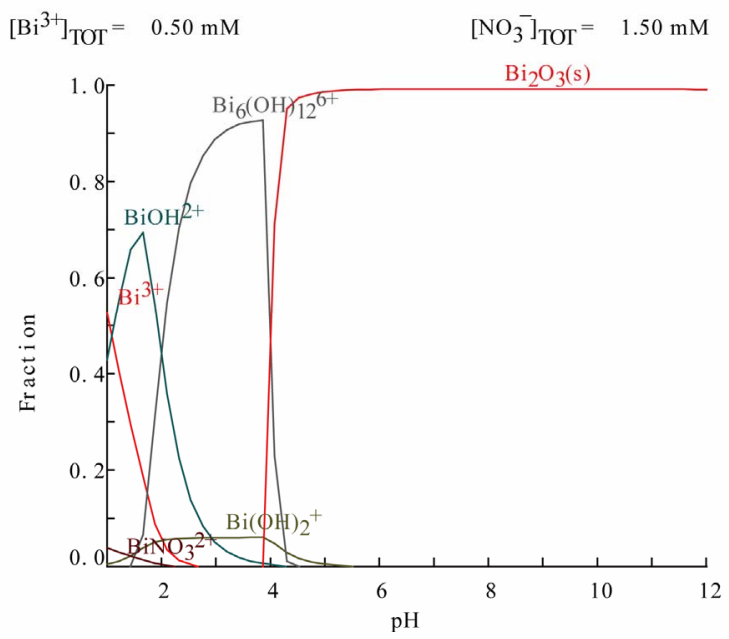

Figure 11. Distribution diagrams of bismuth ion $(0.5$ $\mathrm{mmol} \cdot \mathrm{L}^{-1}$ ) in nitrate media using Medusa and Hydra programs [14].

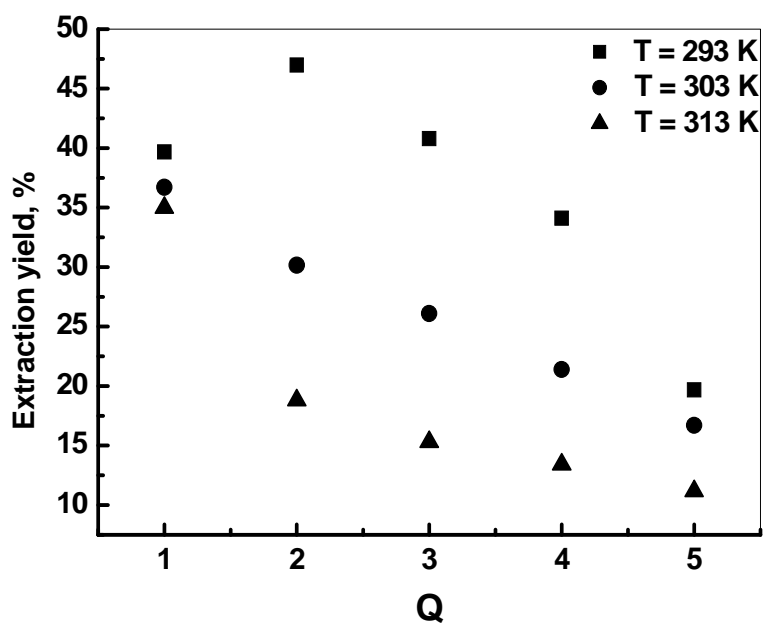

Figure 12. Effet of temperature on the extraction yield $\left[\mathrm{Bi}^{3+}\right]_{0}=5 \times 10^{-4} \mathrm{M}, \mathrm{Vaq} / \operatorname{Vorg}=1, \mathrm{t}=6 \mathrm{~min}, \mathrm{~T}=20^{\circ} \mathrm{C}$. 


\subsection{Effect of Temperature}

The effect of temperature on the extraction of bismuth (III) ions was studied under optimum conditions.

Different thermodynamic parameters were computed using Van't Hoff equation in the form.

$$
\begin{aligned}
\operatorname{InKc} & =-\frac{\Delta H}{\mathrm{RT}}+\frac{\Delta \mathrm{S}}{\mathrm{R}} \\
\Delta \mathrm{G} & =\mathrm{RTLn} \mathrm{Kc}
\end{aligned}
$$

Where $\Delta \mathrm{H}, \Delta \mathrm{S}, \Delta \mathrm{G}$, and $\mathrm{T}$ are the enthalpy, entropy, Gibbs free energy, and temperature in Kelvin, respectively. The values of equilibrium ratio $(\mathrm{Kc})$, were calculated at each temperature using the relationship.

$$
\mathrm{Kc}=\mathrm{Fe} /(1-\mathrm{Fe})
$$

Where $\mathrm{F}_{\mathrm{e}}$ is the fraction of $\mathrm{Bi}(\mathrm{III})$ ions extracted at equilibrium.

$$
\begin{gathered}
\Delta \mathrm{H}=-7.47 \mathrm{KJ} \cdot \mathrm{mol}^{-1} \\
\Delta \mathrm{S}=-29.33 \mathrm{~J} \cdot \mathrm{mol}^{-1} \cdot \mathrm{K}^{-1}
\end{gathered}
$$

The plot of $\log \mathrm{Kc}$ vs $1 / \mathrm{T}$ is a straight line as shown in Figure 13 with correlation coefficient $r=0.9947$. The numerical values of $\Delta \mathrm{H}, \Delta \mathrm{S}$ are computed from the slope. The negative value of Gibbs free energy as shown in Table 1 indicates the spontaneous nature of extraction, while negative value of $\Delta \mathrm{H}$ reflects the exothermic extraction behavior. The negative value of $\Delta S$ indicates the complex stability

\section{Conclusions}

The solvent extraction of the species Bi(III) with ADDMDPA dissolved in chloroform was explained taking into account the formation of different complexes.

In nitrate medium, the extraction kinetic is very fast. The optimal extraction parameters for metal ions concentration of $0.5 \mathrm{mmol} \cdot \mathrm{L}^{-1}$ in the aqueous phase and 1

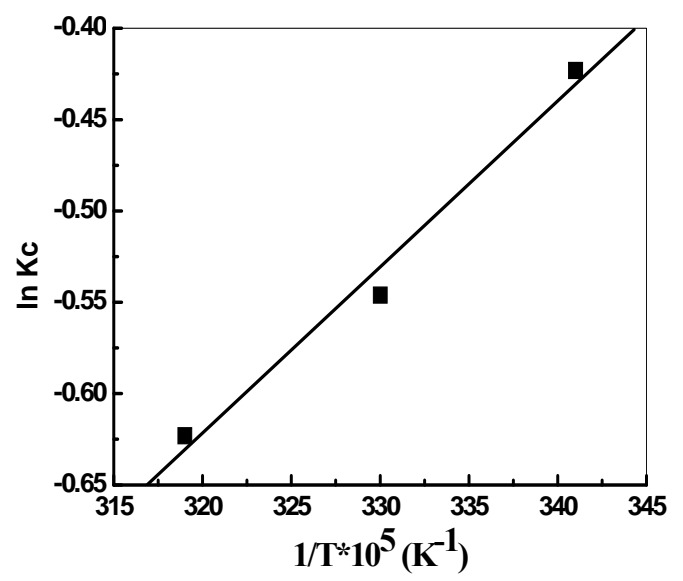

Figure 13. Variation of $\log \mathrm{Kc}$ with $1 / \mathrm{T}$ for the extraction of bismuth(III).
Table 1. Thermodynamic constants of the extraction of bismuth (III)) ions

\begin{tabular}{cc}
\hline Thermodynamic parameters & Values \\
\hline$\Delta \mathrm{H}(\mathrm{KJ} / \mathrm{mol})$ & -7.47 \\
$\Delta \mathrm{S}(\mathrm{J} / \mathrm{mol} \mathrm{K})$ & -29.33 \\
$\Delta \mathrm{G}(\mathrm{KJ} / \mathrm{mol})$ & $-1.029\left(\mathrm{~T}=293^{\circ} \mathrm{C}\right)$ \\
\hline
\end{tabular}

$\mathrm{mmol} \cdot \mathrm{L}^{-1}$ in the organic phase, are $\mathrm{Q}=2, \mathrm{Vaq} /$ Vorg $=1$, $\mathrm{T}=25^{\circ} \mathrm{C}$.

The addition of $\mathrm{CH}_{3} \mathrm{COONa}$ decreased the yield of extraction much while the addition of $\mathrm{KNO}_{3}$ to the same concentration of $0.01 \mathrm{M}$ with increased the extrability of our cation up to $70 \%$ with $\mathrm{Q}=1$.

The increase in the concentration of $\mathrm{H}^{+}$of the aqueous phase had an antagonistic effect on the yield of extraction

\section{Acknowledgements}

We gratefully acknowledge the "Ministère de la Recherche et des Nouvelles Technologies", CNRS (Centre National de la Recherche Scientifique) and the Program TASSILI 10MDU799 for their financial support.

\section{REFERENCES}

[1] M. Burguera, J. L. Burguera, C. Rondon and M. I. Garcia, "Determination of Bismuth in Biological Tissues by Electrothermal Atomic Absorption Spectrometry Using Platinum and Tartaric Acid as Chemical Modifier," Journal of Analytical Atomic Spectrometry, Vol. 16, No. 10, 2001, pp. 1190-1195.

[2] F. Habashi, "Arsenic, Antimony, and Bismuth Production," Encyclopedia of Materials: Science and Technology, 2008, pp. 332-336.

[3] J. D. Jorgenson, "US Geological Survey," Mineral Commodity Summaries, Eastern Region, Reston, 2003, p. 37.

[4] J. A. Reyes-Aguilera, M. P. Gonzalez, R. Navarro, T. I. Saucedo and M. Avila-Rodriguez, "Supported Liquid Membranes (SLM) for Recovery of Bismuth from Aqueous Solutions," Journal of Membrane Science, Vol. 310, No. 1-2, 2008, pp. 13-19.

doi:10.1016/j.memsci.2007.10.020

[5] E. M. Donaldson and M. Wang, "Determination of Silver, Antimony, Bismuth, Copper, Cadmium and Indium in Ores, Concentrates and Related Materials by Atomicabsorption Spectrophotometry after Methyl Isobutyl Ketone Extraction as Iodides," Talanta, Vol. 33. No. 3, 1986, pp. 233-242. doi:10.1016/0039-9140(86)80057-1

[6] J. G. Yang, J. Y. Yang, M. T. Tang, C. B. Tang and W. Liu, "The Solvent Extraction Separation of Bismuth and Molybdenum from a Low Grade Bismuth Glance Flotation Concentrate," Hydrometallurgy, Vol. 96, No. 4, 2009, pp. 342-348. doi:10.1016/j.hydromet.2008.12.006

[7] K. Campos, R. Domingo, T. Vincent, M. Ruiz and A. M. S. Guibal, "Bismuth Recovery from Acidic Solutions Us- 
ing Cyphos IL-101 Immobilized in a Composite Biopolymer Matrix," Water Research, Vol. 42, No. 14, 2008, pp. 4019-4031. doi:10.1016/j.watres.2008.07.024

[8] E. P. Horwitz, H. Diamond, K. A. Martin and R. Chiarizia, "Extraction of Americium (III) from Chloride Media by Octyl(phenyl)-N,N-diisobutylcarbamoylmethylphosphine Oxide," Solvent Extraction and Ion Exchange, Vol. 5, No. 3, 1987, pp. 419-446. doi:10.1080/07366298708918575

[9] D. Villemin, B. Moreau, A. Elbilali, M. A. Didi, M. Kaid and P. A. Jaffres, "Green Synthesis of Poly(aminomethylenephosphonic) Acids," Phosphorus, Sulfur and Silicon, Vol. 185, No. 12, 2010, pp. 2511-2519. doi:10.1080/10426501003724897

[10] A. Buch, M. Stambouli, D. Pareau and G. Durang, "Solvent Extraction of Nickel (II) by Mixture of 2-Ethylhexanal Oxime and Bis(2-ethylhexyl) Phosphoric Acid," Solvent Extraction and Ion Exchange, Vol. 20, No. 1, 2002, pp. 49-66. doi:10.1081/SEI-100108824

[11] M. A. Didi, A. Elias and D. Villemin, "Effect of Chain
Length of Alkane-1-hydroxy-1,1'-methyl Diphosphonics Acids on the Iron (III) Liquid-Liquid Extraction," Solvent Extraction and Ion Exchange, Vol. 20, No. 4-5, 2002, pp. 407-415. doi:10.1081/SEI-120004813

[12] J. R. Ferraro, A. W. Herlinger and R. Chiarizia, "Correlation of the Asymmetric and Symmetric POO Frequencies with the Ionic Potential of the Metal Ion in Compounds of Organophosphorus Acid Extractants: A Short Review," Solvent Extraction and Ion Exchange, Vol. 16, No. 3, 1998, pp. 775-794. doi:10.1080/07366299808934552

[13] P. E. Body, P. R. Dolan and D. E. Mulcahy, "Environmental Lead: A Review," Critical Reviews in Environmental Control, Vol. 20, No. 5-6, 1991, pp. 299-310. doi:10.1080/10643389109388403

[14] I. Puigdomenech, "HYDRA (Hydrochemical EquilibriumConstant Database) and MEDUSA (Make Equilibrium Diagrams Using Sophisticated Algorithms) Programs," Royal Institute of Technology, Sweden. http://www.ke- mi.kth.se/medusa 